\section{(6) OPEN ACCESS}

\title{
Periprocedural safety of aneurysm embolization with the Medina Coil System: the early human experience
}

\author{
Aquilla S Turk, ${ }^{1}$ Orlando Maia, ${ }^{2}$ Christian Candido Ferreira, ${ }^{2}$ Diogo Freitas, ${ }^{2} \mathrm{~J} \mathrm{Mocco,}^{3}$ \\ Ricardo Hanel ${ }^{4}$
}

${ }^{1}$ Department of Radiology and Radiological Sciences, Medical University of South Carolina, Charleston, South Carolina, USA

${ }^{2}$ Department of Neurosurgery, Hospital Santa Teresa, Petropolis, Brazil

${ }^{3}$ Department of Neurosurgery, Mount Saini, New York,

New York, USA

${ }^{4}$ Department of Neurosurgery, Baptist Hospital, Jacksonville, Florida, USA

\section{Correspondence to}

Dr AS Turk, Medical University of South Carolina, Department of Radiology and Radiological Sciences, 96 Jonathan Lucas Street, CSB 210, Charleston, SC 29425, USA; turk@musc.edu

Received 8 December 2014 Revised 2 January 2015 Accepted 9 January 2015 Published Online First 27 January 2015

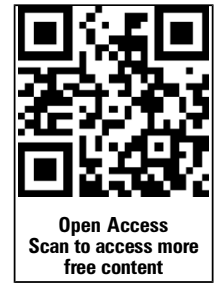

CrossMark

To cite: Turk AS, Maia 0 , Ferreira CC, et al. I Neurolntervent Surg 2016;8:168-172.

\section{ABSTRACT}

Introduction Intracranial saccular aneurysms, if untreated, carry a high risk of morbidity and mortality from intracranial bleeding. Embolization coils are the most common treatment. We describe the periprocedural safety and performance of the initial human experience with the next generation Medina Coil System.

Methods The Medina Coil System is a layered threedimensional coil made from a radiopaque, shape set core wire, and shape memory alloy outer coil filaments. Nine aneurysms in five patients were selected for treatment with the Medina Coil System.

Results Nine aneurysms in five patients, ranging from 5 to $17 \mathrm{~mm}$ in size in various locations, were treated with the Medina Coil System. No procedural or periprocedural complications were encountered. Procedure times, number of coils used to treat the aneurysm, and use of adjunctive devices were much less than anticipated if conventional coil technology had been used.

Conclusions The Medina Coil System is a next generation coil that combines all of the familiar and expected procedural safety and technique concepts associated with conventional coils. We found improved circumferential aneurysm filling, which may lead to improved long term outcomes, with fewer devices and faster operating times.

\section{BACKGROUND}

Endovascular coiling of cerebral aneurysms has become widely accepted as a safe and effective alternative to surgical clipping of cerebral aneurysms. ${ }^{1-4}$ Advancements in technology, such as trackable balloons, self expanding stents, and flow diverters, allow endovascular treatment of most cerebral aneurysms. ${ }^{5-11}$ However, aneurysm residuals or recanalization remains a challenge. To this end, continued effort must be made to advance coil technology in order to improve long term occlusion rates.

The Medina Coil was designed as a next generation coil technology that incorporates the versatility, technical performance, and safety profile of coils with excellent filling capabilities and, hopefully, more robust long term occlusion rates. This report details the initial clinical experience with this next generation three-dimensional coil in order to assess the immediate periprocedural safety in the treatment of cerebral aneurysms.

\section{MATERIALS AND METHODS Device description}

The Medina Coil has been granted CE Mark clearance from the European Union notified body, and is designed to treat all saccular aneurysms of any morphology or location. The Medina Coil is a three-dimensional coil made from a radiopaque, shape set core wire, and shape memory alloy outer filaments that are shaped into petals. The petals lie along the axis of the structure. When deployed, the Medina Coil begins in a linear configuration and then deforms to fill space within the aneurysm. In its unconstrained state, the device retains a linear form with the petals unfolding into a wave form pattern, as shown in figure 1. But, as the device is introduced into an aneurysm, it bends on itself and deforms to both cover the aneurysm ostium as well as to create a stable structure, while still allowing contrast flow for visualization. The Medina Coil is detachable and is manipulated and deployed through a microcatheter. Similar to conventional coils, it can be retracted and repositioned or removed completely, as desired. The threedimensional petals that constitute the coil surrounding filaments form broader 'loops' rather than thinner wires, as with conventional coils, which allows for stable anchoring of the coil within the aneurysm sac. Mechanically, these broad petals broadly distribute the forces exerted on the aneurysm wall. The Medina Coil line constitutes both framing and filler coils. The framing coils provide support and complex into an outer basket. The filler coils are softer, and are designed to fill the internal space within the framing coils.

\section{Procedure}

Patients were selected based on aneurysm size of at least $5 \mathrm{~mm}$ in diameter, as the smallest currently available device is $5 \mathrm{~mm}$ in diameter. Standard endovascular coiling techniques were used. Briefly, a $6 \mathrm{~F}$ groin sheath was used in the groin to allow a $6 \mathrm{~F}$ guide catheter to be placed into the distal cervical vertebral or carotid artery. Patients were heparinized with 5000 units, and no one received antiplatelet agents prior to surgery. A 0.021 inch Prowler (Codman, Nadick, Massachusetts, USA) or 0.021 inch Rebar (Micro Therapeutics, Irvine, California, USA) microcatheter was then used to selectively catheterize the target aneurysm. A Medina Framing Coil was chosen using sizing selection in the same manner as choosing traditional coils. If the deployed coil configuration was felt to be unacceptable at any point during the deployment, the coil could always be retracted and redeployed, consistent with current conventional coils. Once adequate placement was confirmed, the coil was mechanically detached. Subsequent coils were then sequentially 


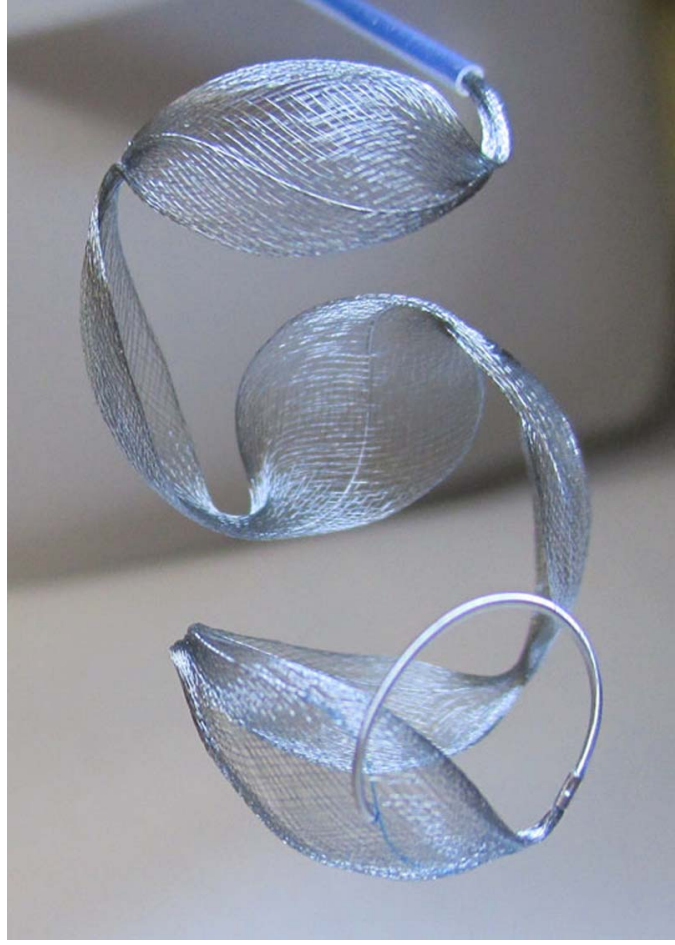

Figure 1 Medina embolization coil in unconstrained space.

placed until placement of further coils was not possible or felt to be unnecessary. Procedure time was defined as the length of time that the microcatheter was present in the aneurysm.

\section{Outcomes}

Angiographic outcomes were classified by per cent filling. Clinical outcomes were documented at discharge by the patients' primary treating physician (OM).

\section{RESULTS}

Nine aneurysms in five patients were treated with the Medina Coil System. Aneurysm locations were middle cerebral $(n=3)$, anterior communicating $(n=2)$, basilar apex, carotid terminus, ophthalmic, posterior communicating, and pericallosal arteries (table 1). All aneurysms were wide necked with a neck to dome ratio $>2: 1$. All aneurysms were treated electively, although one patient had suffered a subarachnoid hemorrhage 1 month prior to treatment and one other patient had bled a year prior to treatment.

All aneurysms were treated with Medina Coils alone, except for one case in which a remaining filling segment at the aneurysm base was too small to accommodate a $5 \mathrm{~mm}$ filling coil, and therefore a traditional coil was used. All cases were performed without any technical or procedural complications. No periprocedural or postprocedure related clinical complications, such as stroke or aneurysm bleeding, were encountered. Acute residual contrast filling within the coil loops was present in all cases except one, where the final device implanted was a conventional coil. One aneurysm treated was a $6 \mathrm{~mm}$ wide necked middle cerebral artery bifurcation aneurysm residual 1 month after surgical clipping. One aneurysm was treated with an Enterprise stent. Procedure time was recorded from the first coil introduced into the microcatheter to the last coil detached.

Table 1 Summary of nine initially treated aneurysms, with location, size, number of coils used, procedure time, and angiographic outcome

\begin{tabular}{|c|c|c|c|c|c|c|c|}
\hline Aneurysm & Aneurysm location & $\begin{array}{l}\text { Aneurysm size } \\
(\mathrm{mm})\end{array}$ & Coils implanted & $\begin{array}{l}\text { Procedure time } \\
\text { (min) }\end{array}$ & $\begin{array}{l}\text { Post-outcome } \\
\text { (\% occlusion) }\end{array}$ & $\begin{array}{l}\text { Adverse/unanticipated } \\
\text { events }\end{array}$ & $\begin{array}{l}1 \text { month follow-up } \\
\text { (\% occlusion) }\end{array}$ \\
\hline 1 & Basilar & $12.1 \times 7.24 \times 5.47$ & $\begin{array}{l}8 \text { Framer } \\
6 \text { Framer } \\
5 \text { Filler } \\
5 \text { Filler } 4 \\
\mathrm{~mm} \times 10 \mathrm{~cm} \\
\text { MicroPlex }\end{array}$ & 48 & 95 & None & 95 \\
\hline 2 & MCA & $8.65 \times 5$ & $\begin{array}{l}7 \text { Framer } \\
5 \text { Filler } \\
5 \text { Filler }\end{array}$ & 8 & $<50$ & None & 95 \\
\hline 3 & Carotid Terminus & $5.2 \times 4.9$ & 6 Framer & 9 & $<50$ & None & 98 \\
\hline 4 & MCA & 6 & 6 Framer & 11 & $<50$ & None & N/A \\
\hline 5 & $\begin{array}{l}\text { Pericallosal (ruptured } \\
1 \text { year prior) }\end{array}$ & $11 \times 4.5$ & $\begin{array}{l}5 \text { Filler } \\
5 \text { Framer }\end{array}$ & 6 & $<50$ & None & N/A \\
\hline 6 & MCA & $7.5 \times 5.6$ & $\begin{array}{l}6 \text { Framer } \\
\text { Enterprise } \\
\text { Stent }\end{array}$ & 5 & $<50$ & $\begin{array}{l}\text { Clot seen on coil, slight } \\
\text { coil protrusion }\end{array}$ & N/A \\
\hline 7 & PCOM & $5.95 \times 4.91$ & 6 Framer & 7 & $<50$ & None & N/A \\
\hline 8 & Ophthalmic & $\begin{array}{l}17 \times 17 \text { with } 9.5 \\
\text { neck }\end{array}$ & $\begin{array}{l}9 \text { Framer } \\
9 \text { Framer } \\
9 \text { Framer } \\
9 \text { Framer } \\
8 \text { Framer } \\
8 \text { Filler } \\
8 \text { Framer }\end{array}$ & 21 & $<60$ & None & None \\
\hline 9 & $\begin{array}{l}\text { ACOM (ruptured } \\
1 \text { month prior) }\end{array}$ & $\begin{array}{l}8.66 \times 14 \text { with } 5.5 \\
\text { neck }\end{array}$ & $\begin{array}{l}8 \text { Framer } \\
7 \text { Framer } \\
5 \text { Filler } \\
6 \text { Filler } \\
5 \text { Filler }\end{array}$ & 33 & $<50$ & None & None \\
\hline
\end{tabular}



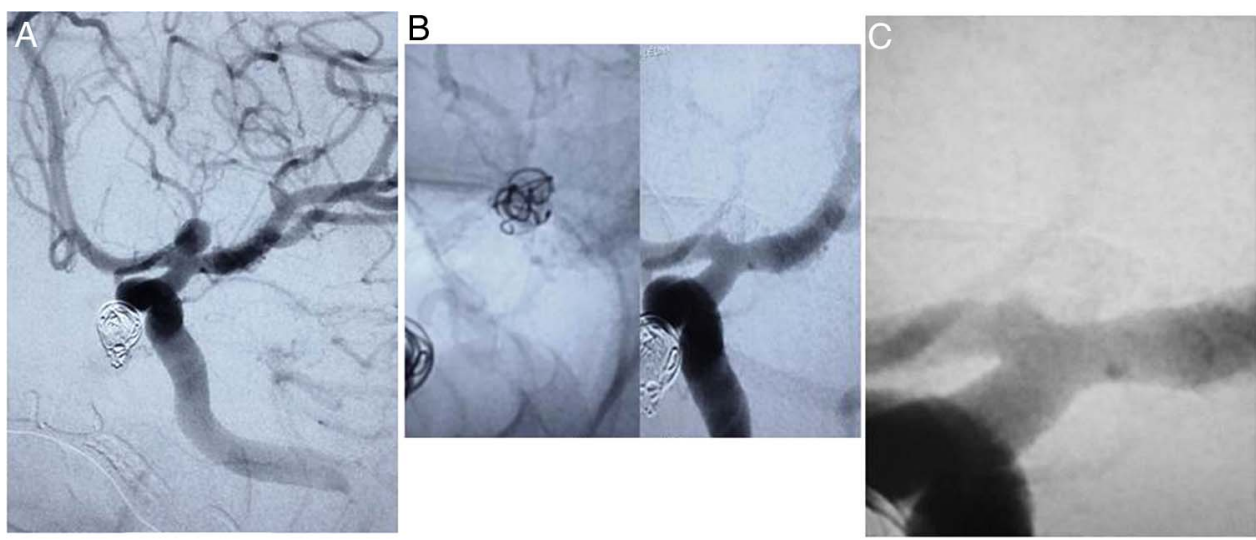

Figure 2 (A) Working frontal digital subtraction angiography (DSA) of a $5 \mathrm{~mm}$ left carotid terminus aneurysm. (B, left) Native magnified working view of the coil mass filling the aneurysm and (right) the same projection DSA of the aneurysm occluded with a very small neck residual. (C) One month follow-up DSA magnified working view with stable aneurysm occlusion and a very small neck remnant.

\section{Illustrative cases}

Aneurysm No 3

A patient with multiple intracranial aneurysms presented for elective endovascular treatment of his aneurysms. The aneurysm at the carotid terminus measured $5.2 \mathrm{~mm} \times 4.9 \mathrm{~mm}$ with a broad neck (figure 2). The aneurysm was treated with a single $6 \mathrm{~mm}$
Medina Framing Coil through a Prowler plus microcatheter with a 9 min procedure time. Control angiography demonstrated significant contrast flow within the coil loops, but apparent stagnation in flow. The patient was discharged home the following day without neurologic complaint. Follow-up angiogram at 1 month was performed during workup to address the

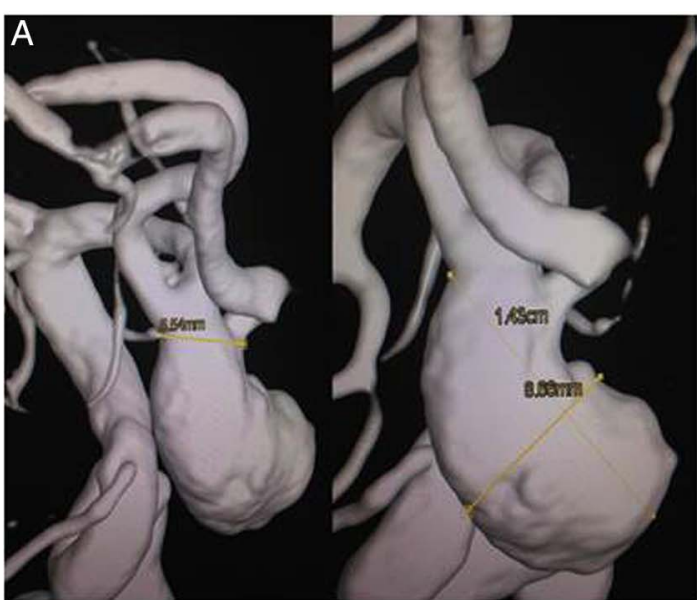

C

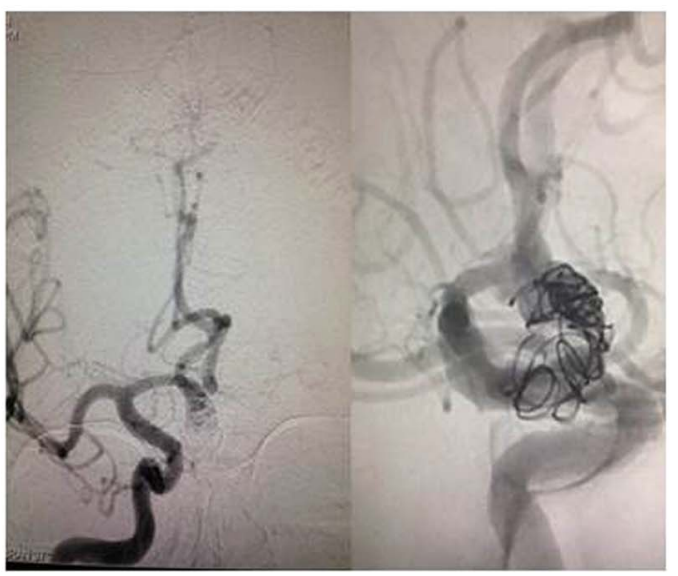

B

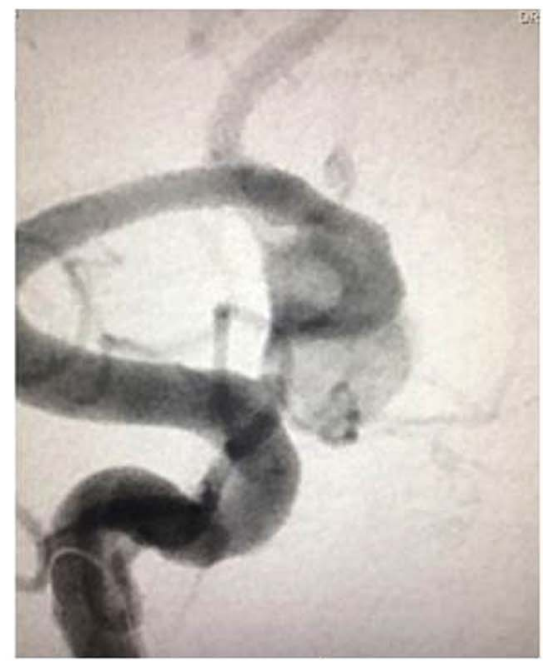

Figure 3 (A, B) A patient who experienced a subarachnoid hemorrhage, 1 month previously, from a $17 \mathrm{~mm} \times 9 \mathrm{~mm}$ with $5.5 \mathrm{~mm}$ neck left anterior communicating region aneurysm, as shown by three-dimensional digital subtraction angiography (DSA) and frontal working view. (C) Final subtracted frontal (left) and native lateral (right) DSA control angiogram showing coils filling the aneurysm, with some contrast penetrating the proximal coil mass and patency of the parent anterior cerebral artery and anterior communicating arteries and their distal branches. 
patient's remaining cerebral aneurysms. Follow-up angiogram demonstrated $>95 \%$ occlusion of the aneurysm with a small neck residual, which was present immediately postprocedure and remained stable in size.

\section{Aneurysm No 9}

This patient experienced a subarachnoid hemorrhage 1 month previously from a $17 \mathrm{~mm} \times 9 \mathrm{~mm}$ with $5.5 \mathrm{~mm}$ neck left anterior communicating region aneurysm (figures 3 and 4). An $8 \mathrm{~mm}$ Medina Framing Coil was used to secure the dome of the aneurysm. A second $7 \mathrm{~mm}$ Median Framing Coil was complexed with the first coil and used to create a proximal basket covering the aneurysm ostium. Complexing framing coils to create a larger or longer coil mass is a common endovascular strategy for oblong and narrow aneurysms or when the aneurysm is much larger than the available coils. The remaining unfilled coil volume within the framing basket was subsequently filled with a $6 \mathrm{~mm}$ Medina Filling Coil and then two $5 \mathrm{~mm}$ filling coils. The final angiogram showed coils filling the aneurysm with some contrast penetrating the proximal coil mass, and the patency of the parent anterior cerebral and anterior communicating arteries and their distal branches. The patient was discharged home the following day without any neurologic complaints.

\section{DISCUSSION}

Wide necked medium and large sized aneurysms remain a common but challenging group of aneurysms in which to effect successful endovascular treatment. Adjunctive devices such as balloons and stents are often required to achieve acceptable endovascular results, but these techniques have been reported to carry a higher risk. $^{5}$ Our early human experience with the Medina Coil, a next generation coil system, demonstrates the familiar coil ease of use methods and periprocedural safety. Additionally, we experienced relatively short procedure times while utilizing few adjunctive technologies.

The reported incidence of residual aneurysm necks after surgical clipping ranges from $3.8 \%$ to $18 \% .^{12}$ Even after complete surgical clipping of an aneurysm, regrowth is thought to occur in up to $15 \%$ and rerupture in $2.7 \%$ of patients. ${ }^{13}$ A large endovascular series demonstrated recanalization rates as high as $42 \%$ in small aneurysms with wide necks. ${ }^{15}$ Large and giant aneurysms demonstrated much higher recanalization rates of $87 \%$ and $90 \% .^{15}$ These limitations continue to drive innovation of new devices, such as flow diverters and bioactive coils. ${ }^{3} 410$

The Medina Coil is, very simply, an advanced coil technology that has some useful similarities with conventional coils, such as device size selection with framers and fillers. The final deployed device construct takes advantage of its surrounding filament design to provide improved volumetric filling of the aneurysm, and to hopefully result in better long term occlusion rates. At this early point of device use, the long term implications are unclear, but the early successful use of the technology in a safe manner consistent with current coil technology is extremely encouraging. To date, three of the Medina treated aneurysms have reached a point at which follow-up angiography was possible. All three demonstrated $>95 \%$ aneurysm occlusion. This limited angiographic follow-up provides an early indication that, like many traditional coils, this device progressively occludes aneurysms over time. These results are particularly exciting given the relative complexity of the aneurysms treated to date.
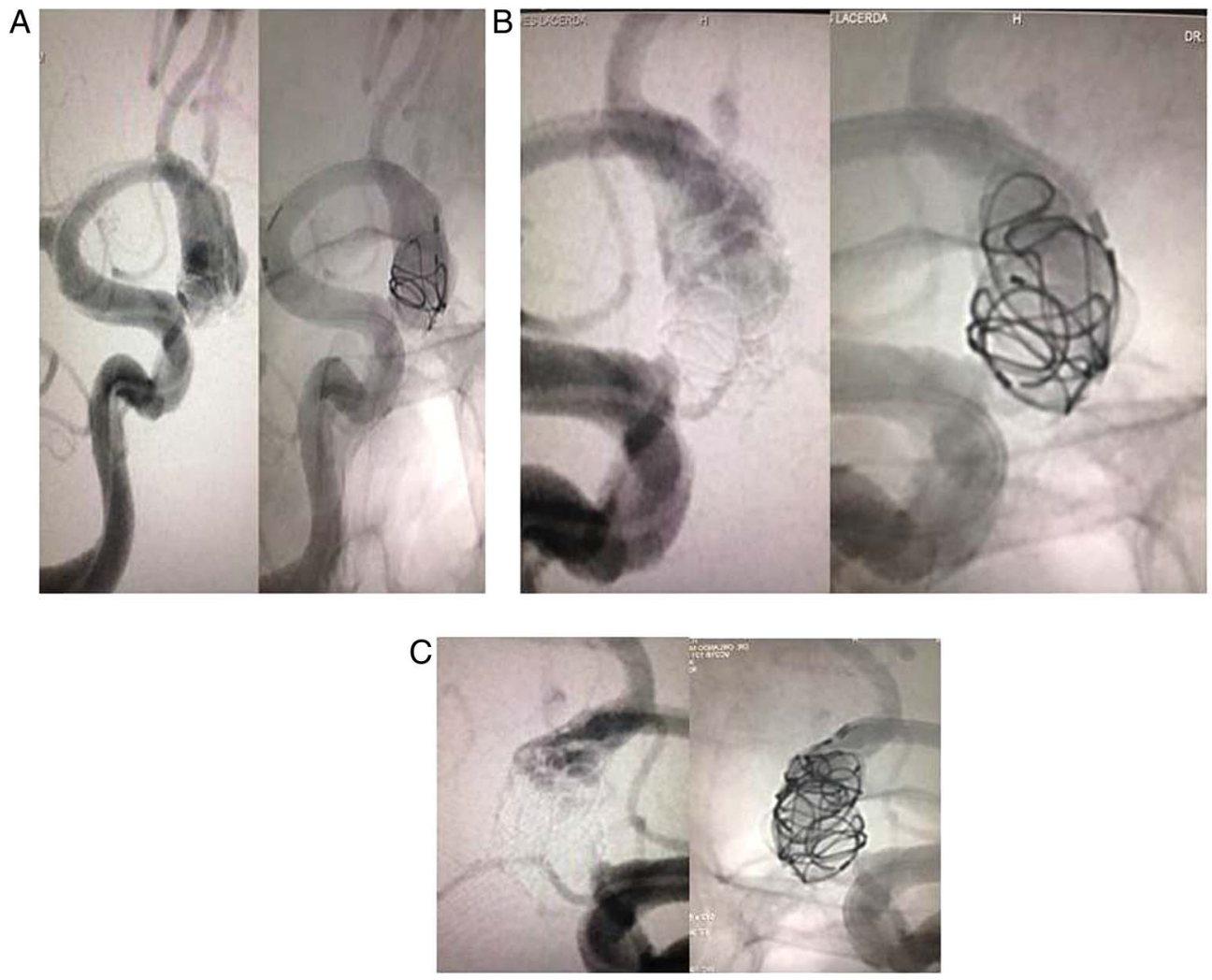

Figure 4 Sequential filling of the aneurysm sac. (A) Subtracted (left) and native (right) digital subtraction angiography (DSA) working view shows an $8 \mathrm{~mm}$ framing coil was used to secure the dome of the aneurysm. (B) Subtracted (left) and native (right) DSA working view shows a second $7 \mathrm{~mm}$ framing coil was complexed with the first coil and used to create a proximal basket covering the aneurysm ostium. (C) Subtracted (left) and native (right) DSA working view shows the remaining unfilled coil volume within the framing basket was subsequently filled with a 6 mm and then two $5 \mathrm{~mm}$ filling coils. 
In our experience, aneurysms treated with conventional coils tend to require about one coil per millimeter in length of the largest aneurysm dimension. Additionally, we feel that the operative risk associated with placement of conventional coils increases as the number of coils placed increases. The Medina Coil was able to treat medium and large aneurysms with fewer coils than we thought would be expected if using conventional coils. An advantage of the Medina Coil design is that it places broader loops at the aneurysm neck that contain future coil loops, minimizing herniation or prolapse into the parent artery. Anecdotally, this seems to improve the safety of placing subsequent coils into the aneurysm. The Medina Coil design was associated with very fast procedure times, with several aneurysms treated in $<10 \mathrm{~min}$.

There are limitations to this report, most significantly that it is a single center, operator adjudicated study. However, the early periprocedural safety of the Medina Coil appears to be well demonstrated. As more delayed angiographic data become available, and larger numbers of aneurysms receive treatment with the Medina Coil, it is possible that this technology will represent a major step forward in endovascular coil embolization of cerebral aneurysms.

\section{CONCLUSION}

The Medina Coil System is a next generation coil that combines the familiar procedural safety and technique concepts associated with conventional coils with improved circumferential aneurysm filling, which it is thought will lead to improved long term outcomes. However, the data presented here demonstrate that, at a minimum, the Medina Coil System can be used safely to effect aneurysm embolization and that, in human cases, it functions in a manner consistent with current conventional coil technology.

Correction notice This article has been corrected since it published Online First. The fourth author's name has been corrected to Diogo Freitas.

Contributors Each author listed above should receive authorship credit based on material contribution to this article, their revision of this article, and their final approval of this article for submission to this journal.

Competing interests RH serves on an advisory board for Medina, is a consultant for Covidien, Stryker, and Codman, and is an investor with Blockade. JM serves as a consultant for Lazarus Effect, Reverse, Pulsar, Edge Therapeutics, and Medina, an investor with Blockade Medical and Medina, and on an advisory board for Codman. AST serves as a consultant for Stryker, Penumbra, Covidien, Codman, and Medpace.

Ethics approval The study was approved by the institutional review board.
Provenance and peer review Not commissioned; externally peer reviewed.

Open Access This is an Open Access article distributed in accordance with the Creative Commons Attribution Non Commercial (CC BY-NC 4.0) license, which permits others to distribute, remix, adapt, build upon this work non-commercially, and license their derivative works on different terms, provided the original work is properly cited and the use is non-commercial. See: http://creativecommons.org/ licenses/by-nc/4.0/

\section{REFERENCES}

1 Molyneux AJ, Kerr RS, Birks J, et al. SAT Collaborators. Risk of recurrent subarachnoid haemorrhage, death, or dependence and standardised mortality ratios after clipping or coiling of an intracranial aneurysm in the International Subarachnoid Aneurysm Trial (ISAT): long-term follow-up. Lancet Neurol 2009;8:427-33.

2 Coley S, Sneade M, Clarke A, et al. Cerecyte coil trial: procedural safety and clinical outcomes in patients with ruptured and unruptured intracranial aneurysms. AJNR Am J Neuroradiol 2012;33:474-80.

3 Cloft HJ. HydroCoil for Endovascular Aneurysm Occlusion (HEAL) study: periprocedural results. AJNR Am J Neuroradiol 2006;27(2):289-92.

4 McDougall CG, Johnston SC, Gholkar A, et al. APS Investigators. Bioactive versus bare platinum coils in the treatment of intracranial aneurysms: the MAPS (Matrix and Platinum Science) trial. AJNR Am J Neuroradiol 2014;35:935-42.

5 Hetts SW, Turk A, English JD, et al. Matrix and Platinum Science Trial Investigators. Stent-assisted coiling versus coiling alone in unruptured intracranial aneurysms in the matrix and platinum science trial: safety, efficacy, and mid-term outcomes. AJNR Am J Neuroradiol 2014;35:698-705.

6 Akpek S, Arat A, Morsi $H$, et al. Self-expandable stent-assisted coiling of wide-necked intracranial aneurysms: a single-center experience. AJNR Am J Neuroradiol 2005;26:1223-31.

7 Byrne JV, Sohn MJ, Molyneux AJ, et al. Five-year experience in using coil embolization for ruptured intracranial aneurysms: outcomes and incidence of late rebleeding. J Neurosurg 1999;90:656-63.

8 Kurre W, Berkefeld J. Materials and techniques for coiling of cerebral aneurysms: how much scientific evidence do we have? Neuroradiology 2008;50:909-27.

9 Pandey AS, Koebbe C, Rosenwasser RH, et al. Endovascular coil embolization of ruptured and unruptured posterior circulation aneurysms: review of a 10-year experience. Neurosurgery 2007;60:626-36.

10 Nelson PK, Lylyk P, Szikora I, et al. The pipeline embolization device for the intracranial treatment of aneurysms trial. AJNR Am J Neuroradiol 2011;32:34-40.

11 Spiotta AM, Miranpuri A, Hawk H, et al. Balloon remodeling for aneurysm coil embolization with the coaxial lumen Scepter $C$ balloon catheter: initial experience at a high volume center. J Neurointerv Surg 2013;5(6):582-5.

12 Brilstra EH, Rinkel GJE, van der Graaf $Y$, et al. Treatment of intracranial aneurysms by embolization with coils: A systematic review. Stroke 1999;30:470-6.

13 Drake CG, Allcock JM. Postoperative angiography and the "slipped" clip. J Neurosurg 1973;39:683-9.

14 Feuerberg I, Lindquist C, Lindqvist $M$, et al. Natural history of postoperative aneurysm rests. J Neurosurg 1987;66:30-4.

15 Viñuela F, Duckwiler G, Mawad M. Guglielmi detachable coil embolization of acute intracranial aneurysm: perioperative anatomical and clinical outcome in 403 patients. J Neurosurg 1997;86:475-82. 